\title{
US Medicare opens door to covering obesity treatments
}

After prompting from the Centers for Disease Control and Prevention in 2001, the US Department of Health and Human Services (HHS) finally removed a clause from its Medicare Coverage Issues Manual in July that stated obesity is not an illness.

This effectively opens the door for Medicare beneficiaries — some 40 million elderly and disabled Americans - to seek coverage for obesity treatments that could include a range of interventions from stomach surgery to nutrition therapy.

The decision won't immediately change what Medicare covers, says Katherine Tillman, spokesperson for the US Centers for Medicare and Medicaid Services. The onus will be on health service providers to submit peer-reviewed, clinical data proving their service or product actually improves the health of Medicare beneficiaries. A panel of government scientists will approve or deny coverage based on that data.

On Aug. 24, the US National Institutes of Health (NIH) announced it is increasing funding for obesity research by approximately $10 \%$ in 2005 to US\$440.3 million.

"There is no doubt that obesity is an epidemic that must be stopped," said HHS Secretary Tommy G. Thompson. "This plan gives us a clear focus for confronting obesity with sciencebased research approaches."

Researchers are now debating whether obesity is the result of genetics, acquired bad habits or other factors.

Dr. Richard Atkinson, cofounder of the American Obesity Association, applauds the decision to declare obesity a disease. "I think obesity is a disease like other diseases. Why should we discriminate against obese people?" says Atkinson who, through his private research company, is studying the possibility of an obesity virus. "I don't have a lot of patience

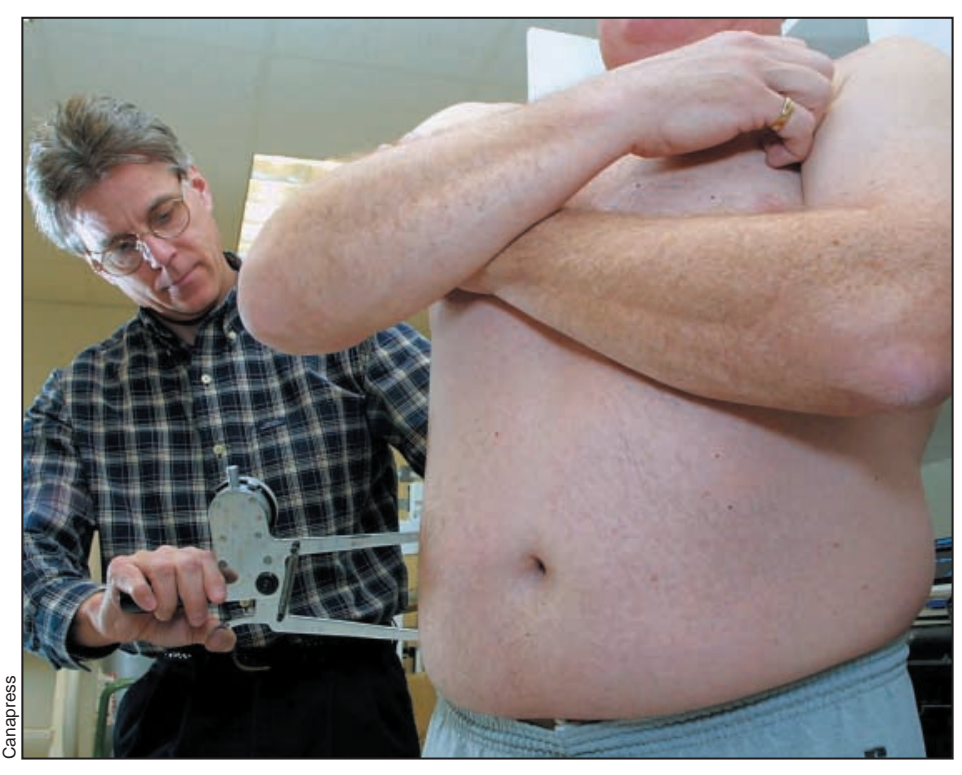

Obesity is officially an illness in the US.

for people who say this is a cultural thing. There is a biological difference between obese people compared to lean."

Government estimates on the cost of obesity-related illnesses in the US in combined out-of-pocket, private insurance and government insurance payouts are about US\$50 million annually. The NIH estimates the total direct and indirect cost of obesity is US\$117 billion annually.

The Centre for Science in the Public Interest, a Washington, DC-based consumer advocacy group, says paying for obesity treatment is a cop-out. "It's crazy to focus so much on treatment of this illness after it's happened rather than on preventive measures," says Executive Director Michael Jacobsen.

Politicians who are serious about addressing obesity, he says, should work toward preventive measures like rearranging food subsidies to favour healthy foods, increasing taxes on unhealthy foods and launching a national media campaign targeting high risk groups like children and the poor.

Dr. William Colmers, a University of Alberta pharmacology professor studying the brain chemistry of hunger, says bad eating habits and inactivity may not be totally to blame for expanding waistlines.

His research indicates that Western diet has affected our natural ability to maintain a healthy weight, creating a mismatch between what the brain thinks the body needs in energy requirements and what it actually needs. He's trying to discover why our appetite shut-off valve is impaired and develop a medication to counteract it.

While debate rages about the causes of obesity - a condition that afflicts nearly 1 in 3 American adults and $32 \%$ of Canadian adults - allied and alternative health care providers are scrambling to gain approval for various treatments.

The American Dieticians Association (ADA) is preparing a package of data to submit to government in the hope medical nutrition therapy will become an accepted treatment under Medicare.

Like many others, the ADA is hopeful private insurers will eventually follow the government's lead by agreeing to cover obesity treatments. - Lisa Gregoire, Edmonton 